Nurhidayat Triananinsi, Fadjriah Ohorella, Marlina Azis, Nurfaizah Alza, Jumrah Sudirman, Mudyawati Kamaruddin

\title{
PEMBERIAN JUS KURMA DAN TEH DENGAN PERCEPATAN PERSALINAN KALA I PRIMIGRAVIDA
}

\author{
Nurhidayat Triananinsi ${ }^{1 *}$, Fadjriah Ohorella ${ }^{2}$, Marlina Azis ${ }^{3}$, Nurfaizah Alza ${ }^{4}$, \\ Jumrah Sudirman ${ }^{5}$, Mudyawati Kamaruddin ${ }^{6 *}$ \\ 1,23,4,5Midwifery Study Program, Megarezky University Makassar South Sulawesi. E-mail: \\ ${ }^{6}$ Fakultas IImu Keperawatan dan kesehatan Universitas Muhammadiyah Semarang \\ *Korespondensi email mudya07@gmail.com
}

\section{ABSTRACTS GIVING DATE JUICE AND TEA WITH ACCELERATION OF FIRST STAGE LABOR OF PRIMIGRAVIDA}

Background: The first stage of labor can be achieved optimally by trying to get contractions. One of the non-pharmacological treatments used to activate the performance of the oxytocin hormone that stimulates uterine contractions can be carried out by supplying additional food intake. This nutrient consumption is typically in the form of a liquid diet containing glucose or carbohydrates. Date juice and tea (teh kotak) are supposed to contain plenty of carbohydrate to provide liquid nutrition in the form of an energy supplier, and can strengthen the contracted uterine muscles to contract.

Purpose: This research was conducted to determine the impact of dates and tea on the smooth progress of the first stage of labor at Kajang Health Center.

Methods: This study consisted of the first latent pregnant women at the Kajang HC with the Post-TestOnly design, and a purposive sampling technique found 40 samples. The samples were split into two groups, pregnant women who received $88.8 \mathrm{ml}$ of date juice, and who received $600 \mathrm{ml}$ of tea during the first stage of labor.

Results: The smoothness of labor was then assessed. This study showed that $75 \%$ of pregnant women who got date juice experienced smooth labor and $25 \%$ had non-smooth labor. Different to whom were given tea, $20 \%$ experienced in smoothness of labor and $80 \%$ has been un-smoothly.

Conclusion Based on the results of research giving date juice and tea to each group of mothers who gave birth during the first stage of active phase at the Kajang Health Center, Bulukumba, it can be concluded that there is a relationship between the provision of date juice and the acceleration of labor during the 1st stage of active phase.

Suggestions We would like to acknowledge the support of the Directorate of Research and Community Service, Directorate General of Research and Development, Ministry of Research, Technology and Higher Education of the Republic of Indonesia, which support through the Research Grant Program for 2020. We appreciate to Megaresky University and Kajang Health Centre, Bulukumba South Sulawesi for providing services, assistance and cooperation in this study.

Keyword: Date Juice, Tea, Smoothness of Labor

\section{ABSTRAK}

Latar Belakang: Persalinan kala I dapat dicapai secara optimal dengan berusaha mendapatkan kontraksi. Salah satu pengobatan nonfarmakologi yang digunakan untuk mengaktifkan kinerja hormon oksitosin yang merangsang kontraksi rahim dapat dilakukan dengan pemberian asupan makanan tambahan. Konsumsi zat gizi ini biasanya berupa makanan cair yang mengandung glukosa atau karbohidrat. Jus kurma dan teh seharusnya mengandung banyak karbohidrat untuk memberikan nutrisi cair berupa pemasok energi, dan dapat memperkuat otot rahim yang berkontraksi untuk berkontraksi.

Tujuan: Penelitian ini dilakukan untuk mengetahui pengaruh kurma dan teh terhadap kelancaran persalinan kala I di Puskesmas Kajang.

Metode: Penelitian ini terdiri dari ibu hamil laten pertama di Puskesmas Kajang dengan desain Post-TestOnly, dan teknik purposive sampling didapatkan 40 sampel. Sampel dibagi menjadi dua kelompok, ibu hamil yang menerima $88,8 \mathrm{ml}$ jus kurma, dan yang menerima $600 \mathrm{ml}$ teh selama kala satu persalinan.

Hasil: Kelancaran persalinan kemudian dinilai. Penelitian ini menunjukkan bahwa $75 \%$ ibu hamil yang mendapat sari kurma mengalami persalinan lancar dan 25\% mengalami persalinan tidak lancar. Berbeda dengan yang diberi teh, $20 \%$ mengalami kelancaran persalinan dan $80 \%$ mengalami tidak lancar. 


\section{JKM (Jurnal Kebidanan Malahayati),Vol 7,No.3.Juli 2021, ISSN (Print) 2476-8944 ISSN (Online) 2579-762X, Hal 528-532}

Kesimpulan Berdasarkan hasil penelitian pemberian sari kurma dan teh pada masing-masing kelompok ibu bersalin kala I fase aktif di Puskesmas Kajang Bulukumba dapat disimpulkan bahwa ada hubungan antara pemberian sari kurma dan percepatan persalinan selama kala 1 fase aktif.

Saran Kami mengucapkan terima kasih yang sebesar-besarnya atas dukungan Direktorat Riset dan Pengabdian kepada Masyarakat, Direktorat Jenderal Penelitian dan Pengembangan, Kementerian Riset, Teknologi, dan Pendidikan Tinggi Republik Indonesia yang telah mendukung melalui Program Hibah Penelitian Tahun 2020. kepada Universitas Megaresky dan Puskesmas Kajang Bulukumba Sulawesi Selatan yang telah memberikan pelayanan, bantuan dan kerjasamanya dalam penelitian ini.

Kata kunci : Jus Kurma, Teh, Kelancaran Persalinan

\section{PENDAHULUAN}

Persalinan merupakan proses normal yang ditandai dengan kontraksi rahim yang menyebabkan dilatasi serviks yang signifikan disertai dengan keluarnya janin dan plasenta dari tubuh wanita (Azis et al., 2020; Begley et al., 2019). Asupan nutrisi diprioritaskan untuk memenuhi energi yang dibutuhkan untuk kontraksi uterus. Proses persalinan kala satu fase aktif melibatkan banyak energi, sehingga kebutuhan nutrisi kala satu perlu mendapat perhatian khusus dari pengelola persalinan (Pascawati et al., 2019). Pemenuhan gizi ibu hamil selama persalinan dapat dilakukan dengan pemberian makanan cair (Erniawati \& Kamaruddin, 2020). Makanan cair adalah jenis makanan yang memiliki konsistensi cair hingga kental. Makanan yang menyediakan makanan cair dan mudah dicerna seperti teh dan air gula (Hendarti, 2019).

Faktor risiko yang mempengaruhi persalinan adalah kekurangan gizi pada kala I persalinan yang dapat berkontribusi pada persalinan lama (Kordi et al., 2017; Lothian, 2019). Nutrisi bagi ibu bersalin, khususnya persalinan kala I, dapat diperoleh dari makanan yang mengandung sumber energi yang cukup tinggi (Kamaruddin, Jusni, et al., 2019). Salah satu buah yang mengandung energi cukup besar adalah kurma yang mengandung fruktosa dan glukosa, yang semuanya merupakan sumber energi yang mudah diserap tubuh (Kamaruddin, Hasrawati, et al., 2019).

Selain itu, kurma mengandung vitamin B1, yang sangat membantu dalam mengatur laju pergerakan rahim dan meningkatkan waktu sistol. Kurma juga mengandung hormon potuchin, yang digunakan untuk menghubungkan rahim dan otot rahim sehingga dapat membantu mencegah pendarahan pada wanita saat melahirkan (Kordi et al., 2017).

Beberapa penelitian menunjukkan bahwa teh mengandung lebih sedikit gula dan mengandung vitamin B kompleks sehingga meningkatkan kontraksi otot rahim yang mempengaruhi kontraksi selama persalinan (Sendra et al., 2016).

Berdasarkan data awal dari Puskesmas Kajang, sebagian besar ibu hamil kala I persalinan meminum teh yang dipercaya dapat mempercepat proses persalinan. Penting untuk dilakukan penelitian dengan membandingkan kala 1 persalinan yang dipercepat dengan pengobatan jus kurma dan teh.

\section{METODOLOGI PENELITIAN}

Penelitian ini dilakukan di Puskesmas Kajang Kabupaten Bulukumba. Penelitian ini merupakan studi banding untuk mengetahui perbandingan dua perlakuan dengan desain posttest-only, yaitu perhitungan yang hanya dilakukan pada akhir penelitian. Populasi penelitian ini adalah ibu bersalin sebanyak 86 orang. Populasi penelitian ini adalah 86 ibu hamil, menggunakan teknik purposive sampling dengan kriteria inklusi: primigravida, 2) persalinan normal tanpa komplikasi, 3) persalinan aktif bukaan $4 \mathrm{~cm}$. Sedangkan kriteria eksklusi adalah ibu yang tidak menyukai teh dan jus kurma. Kemudian diambil 40 responden sebagai sampel penelitian berdasarkan kriteria penyaringan. Penelitian dibagi menjadi dua kategori yaitu kelompok ibu-ibu yang diberi sari kurma (hasil produksi CV amal mulia sejahtera) sebanyak 88,8 $\mathrm{ml}$ (6 sendok makan) dan kelompok ibu-ibu yang diberi teh $600 \mathrm{ml}$ (produksi PT. Ultrajaya Milk Industry tbk) selama persalinan kala $I$, dengan masing-masing kelompok perlakuan terdiri dari 20 responden. Kelancaran persalinan diukur, mulai dari awal kontraksi uterus dan pembukaan serviks sampai tercapai pembukaan penuh. Persalinan yang lancar harus dipertimbangkan jika persalinan berlangsung kira-kira 6 jam selama tahap pertama dari proses aktif. Sedangkan jika berlangsung 6 jam, persalinan tidak lancar.

Teknik analisis data menggunakan analisis univariat variabel penelitian, yang kemudian didefinisikan dan disajikan dalam tabel distribusi frekuensi. Sedangkan analisis bivariat dilakukan 


\section{Nurhidayat Triananinsi, Fadjriah Ohorella, Marlina Azis, Nurfaizah Alza, Jumrah Sudirman, Mudyawati Kamaruddin}

untuk mengevaluasi perbandingan antara sari kurma dan teh kemasan yang diberikan terhadap kelancaran persalinan kala I menggunakan uji ChiSquare (Syamsunie, 2018).

\section{HASIL DAN PEMBAHASAN}

Dari 80 ibu hamil yang akan melahirkan, hanya 40 yang berhasil dijadikan sampel dan diberikan dengan jus kurma dan teh, tergantung pada sebaran kelompok perlakuan. Hasil analisis univariat pada kelompok perlakuan jus kurma menunjukkan bahwa responden lebih banyak adalah orang dewasa (20-35 tahun), yaitu $55 \%$. Sedangkan jenjang pendidikan menengah atas (SMA) terakhir adalah $55 \%$. Demikian pula sebaran responden pada kelompok perlakuan teh menunjukkan bahwa usia dewasa lebih dominan yaitu $50 \%$, dan jenjang pendidikan terakhir didominasi oleh SMA (Tabel 1).

Table 1.

Distribusi Responden Berdasarkan Karakteristik Ibu Melahirkan

\begin{tabular}{llcc}
\hline \multirow{2}{*}{ Karakteristik responden } & \multicolumn{1}{c}{ Kategori } & \multicolumn{2}{c}{ Jumlah Responden } \\
\cline { 3 - 4 } & & $\mathbf{N}=\mathbf{4 0}$ & $\%$ \\
\hline Intervensi dengan jus kurma & & 8 & 40 \\
Usia & 20 tahun & 11 & 55 \\
& $20-35$ tahun & 1 & 5 \\
Pendidikan & $>35$ tahun & 2 & 10 \\
& Sekolah Dasar & 7 & 35 \\
Intervensi Teh (Teh Kotak) & SMP & 11 & 55 \\
Usia & SMA & & \\
& & 9 & 45 \\
Pendidikan & $<20$ tahun & 10 & 50 \\
& 20-35 tahun & 1 & 5 \\
& $>35$ tahun & 3 & 15 \\
& Sekolah Dasar & 4 & 20 \\
& SMP & 13 & 65 \\
\hline
\end{tabular}

Table 2.

Hasil Analisis bivariat pemberian sari kurma dan teh terhadap kelancaran persalinan

\begin{tabular}{|c|c|c|c|c|c|c|c|}
\hline \multirow{3}{*}{ Kategori melahirkan } & \multicolumn{4}{|c|}{ Intervensi } & \multirow{2}{*}{\multicolumn{2}{|c|}{$\begin{array}{c}\text { Total } \\
\mathrm{N}=40\end{array}$}} & \multirow{3}{*}{$\rho$ value } \\
\hline & \multicolumn{2}{|c|}{ Jus Kurma } & \multicolumn{2}{|c|}{ Teh } & & & \\
\hline & $\mathrm{N}$ & $\%$ & $\mathbf{N}$ & $\%$ & $\mathrm{~N}$ & $\%$ & \\
\hline Persalinan Lancar & 15 & 75 & 4 & 20 & 19 & 7,5 & \\
\hline Persalinan tidak lancar & 5 & 25 & 16 & 80 & 21 & 52,5 & 0,002 \\
\hline Total & 20 & 100 & 20 & 100 & 40 & 100 & \\
\hline
\end{tabular}

Hasil analisis bivariat menunjukkan bahwa jumlah kelancaran persalinan dari kelompok responden yang menerima jus kurma adalah $75 \%$ atau 15 orang, lebih banyak dari pada kelompok responden yang menerima teh yang hanya 4 orang (Tabel 2).

\section{PEMBAHASAN}

Persalinan adalah suatu cara mengeluarkan kehamilan (janin dan plasenta) yaitu kehamilan sembilan bulan atau dapat bertahan hidup di luar kandungan dengan cara lain, dengan atau tanpa bantuan (Chen et al., 2018). Proses ini dimulai dengan kontraksi persalinan yang spesifik, yang ditandai dengan pergeseran serviks secara bertahap dan diakhiri dengan lahirnya plasenta (Geltore et al., 2018). Jus kurma mengandung beberapa stimulan yang dapat memperbaiki otot rahim saat melahirkan. Ini membantu meningkatkan kontraksi rahim saat melahirkan. Sari kurma merupakan buah yang tinggi nutrisi dan mengandung karbohidrat, serat, kalsium, dan vitamin B (Bolsinger et al., 2014). Sedangkan teh mengandung vitamin $B$ kompleks, vitamin $C$, vitamin $E$, karatein untuk meningkatkan sistem metabolisme tubuh dan kandungan glukosa dalam teh, dapat menjadi sumber energi sebagai 
JKM (Jurnal Kebidanan Malahayati),Vol 7,No.3.Juli 2021,

ISSN (Print) 2476-8944 ISSN (Online) 2579-762X, Hal 528-532

pengganti energi yang hilang selama persalinan kala I.

Hasil analisis bivariat menunjukkan bahwa terdapat hubungan yang kuat antara pemberian jus kurma pada ibu bersalin di Puskesmas Kajang, dan temuan ini sejalan dengan penelitian Jayanti ID (Jayanti, nd) yang mempelajari pengaruh konsumsi sari kurma dan air gula pada ibu kala I persalinan. Hal yang sama dilakukan oleh Febriyanti dan Moita (2018) menunjukkan bahwa terdapat hubungan antara percepatan persalinan kala I fase aktif kelompok jus kurma di RS Citra Insani Kota Semarang (Febriyanti \& Moita, 2018). ). Kelancaran persalinan kala I ditentukan oleh pemberian nutrisi cair yang diperoleh dari jus kurma yang mengandung fruktosa dan glukosa sebagai pengganti sumber energi yang dibutuhkan ibu untuk mengatasi kelelahan akibat kontraksi pada kala I persalinan. Selain fakta bahwa jus kurma mengandung bentuk hormon oksitosin yang tidak tersedia pada teh. Hormon ini disebut oksitosin berdasarkan efek fisiologisnya, seperti percepatan persalinan dengan menginduksi kontraksi otot polos rahim. Oksitosin inilah yang akan dilepaskan ke dalam darah (Jayanti, n.d.; Kusmiwiyati \& Triningsih, 2018).

Ibu yang mengonsumsi jus kurma membuat penggunaan oksitosin lebih sedikit dibandingkan ibu yang mengonsumsi teh (Kusmiwiyati \& Triningsih, 2018). Dari sini terlihat adanya perbedaan pengaruh pemberian jus kurma dan teh dalam mempercepat kala I. Selama persalinan, ibu akan membutuhkan banyak energi, seperti karbohidrat, gula dan vitamin B1, untuk membantu mengatur laju pergerakan rahim dan meningkatkan sistol. Sari kurma juga mengandung zat besi dan kalsium yang dapat dengan mudah menggantikan tenaga ibu yang terkuras saat melahirkan (Kamaruddin, Hasrawati, dkk., 2019; Lothian, 2019). Berbeda dengan teh yang hanya mengandung vitamin $B$ kompleks dan sedikit gula, sehingga dapat menyebabkan persalinan tidak lancar

\section{SIMPULAN}

Berdasarkan hasil penelitian pemberian sari kurma dan teh pada masing-masing kelompok ibu bersalin kala I fase aktif di Puskesmas Kajang Bulukumba dapat disimpulkan bahwa ada hubungan antara pemberian sari kurma dengan percepatan persalinan selama tahap 1 fase aktif.

\section{SARAN}

Kami mengucapkan terima kasih atas dukungan Direktorat Riset dan Pengabdian kepada Masyarakat, Direktorat Jenderal Riset dan
Pengembangan, Kementerian Riset, Teknologi, dan Pendidikan Tinggi Republik Indonesia yang telah mendukung melalui Program Hibah Penelitian Tahun 2020. Universitas Megaresky dan Puskesmas Kajang Bulukumba Sulawesi Selatan yang telah memberikan pelayanan, bantuan dan kerjasama dalam penelitian ini.

\section{DAFTAR PUSTAKA}

Azis, M., Alza, N., Triananinsi, N., Pertiwi, A. Y. D., \& Kamaruddin, M. (2020). Efektivitas Senam Hamil terhadap Kelancaran Persalinan Kala II pada Ibu Inpartu di Puskesmas Bulupoddo Kabupaten Sinjai. Medika Alkhairaat: Jurnal Penelitian Kedokteran dan Kesehatan, 2(2), 187-191.

Begley, C. M., Gyte, G. M., Devane, D., McGuire, W., Weeks, A., \& Biesty, L. M. (2019). Active versus expectant management for women in the third stage of labour (Review). Cochrane Database of Systematic Reviews, 2, 142.

Bolsinger, J., Pronczuk, A., Sambanthamurthi, R., \& Hayes, K. C. (2014). Anti-diabetic effects of palm fruit juice in the Nile rat ( Arvicanthis niloticus ). Journal of Nutritional Science, 3 , e5. https://doi.org/10.1017/jns.2014.3

Chen, H., Cao, L., Cao, W., Wang, H., Zhu, C., \& Zhou, R. (2018). Factors affecting labor duration in Chinese pregnant women. 97(52), 1-8. http://dx.doi.org/10.1097/MD.000000000001 3901

Erniawati, \& Kamaruddin, M. (2020). Asuhan Kebidanan Pasca Salin (1 ${ }^{\text {st }}$ ed.). Manggu Makmur Tanjung Lestari.

Febriyanti, S. N. U., \& Moita, P. H. (2018). Perbedaan Lama Persalinan Ibu Bersalin yang Diberikan Susu Formula dan Teh. 1, 166-169.

Geltore, T. E., Taye, A., \& Kelbore, A. G. (2018). Utilization of obstetric analgesia in labor pain management and associated factors among obstetric caregivers in public health facilities of Kembata Tembaro Zone, Southern Ethiopia. Journal of Pain Research, 11, 3089-3097. https://doi.org/10.2147/JPR.S165417

Hendarti, E. S. (2019). Kepatuhan Intake Cairan dan Proses Persalinan pada Pasien PEB di RSUD Jombang. Artikel, 7(1), 1-6.

Jayanti, I. D. (n.d.). Lama Kala I Fase Aktif Ibu Bersalin yang Mengkonsumsi Asupan Sari Kurma dan Air Gula. 1(1), 13-17.

Kamaruddin, M., Hasrawati, Usmia, S., Jusni, Misnawaty, \& Handayani, I. (2019). Korelasi 


\section{Nurhidayat Triananinsi, Fadjriah Ohorella, Marlina Azis, Nurfaizah Alza, Jumrah Sudirman, Mudyawati Kamaruddin}

antara Status Gizi dan Kadar Hemoglobin pada Kejadian Anemia Ibu Hamil Trimester III. 1(2), 77-82.

Kamaruddin, M., Jusni, \& Nurul A Sari. (2019). Persepsi dan Pengetahuan Mahasiswa Akademi Kebidanan Tahirah Al Baeti terhadap Gizi Remaja. 1(3), 108-112.

Kordi, M., Meybodi, F. A., Tara, F., Fakari, R., Nemati, M., \& Shakeri, M. (2017). Effect of Dates in Late Pregnancy on the Duration of Labor in Nulliparous Women. Wolters Kluwer-Medknow, 22, 383-387. https://doi.org/10.4103/ijnmr.IJNMR_213_15

Kusmiwiyati, A., \& Triningsih, R. W. (2018). Hubungan Pijat Oksitosin Dengan Penurunan TFU dan Pengeluaran Lochea pada Ibu Postpartum Normal. Jurnal Kebidanan, X(2), 60-69.
Lothian, J. A. (2019). Healthy Birth Practice \#4: Avoid Interventions Unless They Are Medically Necessary. The Journal of Perinatal Education, 28(2), 94-103. http://dx.doi.org/10.1891/1058-1243.28.2.94

Pascawati, R., Shahib, N., \& Husin, F. (2019). Pengaruh Pemberian Minuman Mix Juice terhadap Kadar Glukosa Darah dan Kebugaran Ibu Bersalin. Jurnal Kesehatan, 10(1), $1-9$. https://doi.org/10.26630/jk.v10i1.1181

Sendra, E., Pratamaningtyas, S., \& Panggayuh, A. (2016). Pengaruh Konsumsi Kurma (Phoenix dactylifera) terhadap Kenaikan Kadar Hemoglobin pada Ibu Hamil Trimester II di Wilayah Puskesmas Kediri. 5(1), 96-104.

Syamsunie, C. H. (2018). Metode Penelitian. Sibuku. 